\title{
Evaluation of Airway Responses by Measurement of the Respiratory Resistance in Rats under Nonanesthetized Conditions
}

\author{
Noboru Tamaki, M.D., ${ }^{*}$ Kazuhiko Hanashiro, M.D., ${ }^{*}$ Shigeru Saitoh, M.D., ${ }^{*}$ \\ Mariko Nakamura, Ph.D., M.D., ${ }^{*}$ and Tadayoshi Kosugi, M.D.*** \\ *Department of Physiology and ${ }^{* *}$ The Research Center of Comprehensive Medicine, \\ School of Medicine, University of the Ryukyus, Okinawa
}

\begin{abstract}
In this study, the airway responses of sensitized rats after antigen exposure were evaluated under nonanesthetized conditions. Prior to measuring the respiratory resistance and evaluating the airway responses, the effect of anesthetics on the increase in respiratory resistance induced by acetylcholine, the responsiveness of tracheal strips derived from sensitized rats towards antigen (DNBS-As), the time required for the nebulization of DNBS-As and changes in the antigenicity of the antigen during nebulization were examined. In addition, based on the results obtained, the conditions for measuring the respiratory resistance of rats were decided as follows: some anesthetics inhibited an increase in the respiratory resistance of rats, and therefore the respiratory resistance of rats should be measured under nonanesthetized conditions. The nebulization time for DNBS-As was set at $5 \mathrm{~min}$, and the concentration of DNBS-As set at $1 \mathrm{mg} / \mathrm{ml}$. Next, in order to evaluate airway responses, the respiratory resistance of sensitized rats under nonanesthetized conditions was measured with an Animal Asto TMC-2000 under the above conditions. The appearance rate for early phase responses 16-30 days after sensitization was higher than that 8-15 days after sensitization. On the other hand, the appearance rate for late phase responses 8-15 days after sensitization was higher than that 16-30 days after sensitization. Based on these results, it can be suggested that the late phase response appears more easily when the level of $\operatorname{IgE}$ antibody in the circulating blood is high.
\end{abstract}

Key words : airway response, respiratory resistance, rats, nonanesthetized condition

Airway responses in allergic asthma following antigen exposure have been classified into 3 types (immediate asthmatic response (IAR), late asthmatic response (LAR), hyperresponse of the airways) according to time of development and duration of response. ${ }^{1 \sim 3)}$ The LAR plays an important role in clinical asthma as a result of the continuous symp-

Address for reprints: Noboru Tamaki, M.D., Department of Physiology, School of Medicine, University of the Ryukyus, 207 Uehara, Nishiharacho, Okinawa 903-01

Received: February 27, 1995 toms following antigen exposure. In addition, the development of a LAR and increased hyperresponsiveness of the airways may be associated with infiltrating inflammatory cells. ${ }^{4,5)}$ In general, the production of a specific IgE antibody may be related to LAR development in humans. ${ }^{6,7)}$ Rabbits, ${ }^{8,9)}$ guinea pigs, ${ }^{10)}$ monkeys, ${ }^{11)}$ sheep $^{12)}$ and rats $^{13)}$ have been used as animal models for LAR. We therefore considered that rats would provide the most suitable animal model for LAR from the standpoint of $\operatorname{IgE}$ production.

In a previous study, we induced airway hyperresponsiveness (AHR) in rats under 
anesthesia and evaluated it employing a modified method of Stotland and Share. ${ }^{14,15)}$ The anesthetic, Nembutal ${ }^{\circledR}$, has frequently been used in animal experiments on rats to analyse the condition of respiration on mod els of asthma. However, it has been suggested that pentobarbital sodium (Nembutal ${ }^{\circledR}$ ) can inhibit the calcium influx of platelets by PAF. ${ }^{16)}$ Accordingly, we thought that it would be more appropriate to evaluate the airway response and hyperresponsiveness of rats under nonanesthetized conditions. It is difficult, however, to evaluate physiologically the changes of respiratory function in experimental animals following exposure to antigen. Until now there have been no reports on the respiratory resistance of rats measured by means of oscillation without anesthesia, although that of guinea pigs has been measured by means of oscillation. ${ }^{17,18)}$

In this study, we attempted to estimate the respiratory resistance of rats by the method of oscillation as far as possible under physiological conditions without anesthesia. Prior to evaluating the respiratory resistance, we determined the contraction of tracheal strips from the rats. In addition, we examined the relationship between the appearance rate for airway responses and the quantity of $\operatorname{IgE}$ in the circulating blood of sensitized rats.

\section{MATERIALS AND METHODS}

\section{Animals}

Wistar and Brown-Norway strain male rats weighing 200 to $400 \mathrm{~g}$ were used for the experiments. The Wistar rats were purchased from Kyudo Co., Ltd. (Kumamoto, Japan) and the Brown-Norway rats from Seiwa Experimental Animals, Ltd. (Fukuoka, Japan).

\section{Methods}

1) Preparation of Tracheal Strips and Measurement of Their Contraction

Rats were anesthetized with $30 \%$ urethane $(3 \mathrm{ml} / \mathrm{kg}$, i.p.). The cervical region of the rats was incised and the trachea was removed. The removed trachea was placed in Tyrode solution. Four tracheal strips were prepared. They consisted of the 1st, 5th, 10th and 15th tracheal cartilage rings. ${ }^{19,20)}$ These tracheal strips were suspended vertically in a Magnus tube containing Tyrode solution. The Tyrode solution was warmed with water at $37^{\circ} \mathrm{C}$ circulated by means of a water pump (ColeParmer Instrument Ltd., IL, USA). Furthermore, air was sent into the Magnus tube using a pump (Cole-Parmer Instrument Ltd., IL, USA) with a speed controller (ColeParmer Instrument Ltd., IL, USA). The lower side of the tracheal strip in the Magnus tube was connected to a serrefine, and the strand from the serrefine was attached to a supporting bar. The upper side of the tracheal strip was clipped by a serrefine with a strand, and this strand was connected to an isotonic transducer (UT-202, Kishimoto Medical Co., Ltd., Fukuoka, Japan) with a constant weight of $0.5 \mathrm{~g}$. The isotonic transducer was connected to an AMP (ITM-102, Iwashiya Kishimoto Medical Instrument Inc., Fukuoka, Japan) and the AMP was linked to an X.Y recorder (200-160, Hitachi Co., Ltd., Tokyo, Japan).

In this experiment, the concentration of acetylcholine ranged from $10^{-9}$ to $10^{-1} \mathrm{M}$, and the concentration of DNBS-As antigen ranged from $10^{-4}$ to $10^{-1} \mathrm{mg} / \mathrm{ml}$. Prior to examining the contraction of the tracheal strips following the addition of acetylcholine to the Magnus tube, they were suspended in Tyrode solution for 15 to $30 \mathrm{~min}$. At the time of the exchange of various concentrations of acetylcholine in the Magnus tube, the tracheal strips were washed 3 times with Tyrode solution, and when their length had returned to its state before the start of the experiment, acetylcholine was again added to the Magnus tube.

2) Preparation of Antigen

Ascaris suum was collected from the intestinal tract of a pig at the Okinawa Meat Hygiene Inspection Center (Okinawa, Japan). 
Protein was extracted from the Ascaris suum according to the method of Strejan and Campbell. ${ }^{21)}$ DNBS-As was prepared according to the method of Eisen et al. ${ }^{22)}$

3) Immunization Procedure

Rats were sensitized with killed Bordetella pertussis $\left(10^{10}\right.$ organisms ; Kaken Inc., Osaka, Japan) and $1 \mathrm{mg}$ of DNBS-As, which were administered into the 4 foot-pads according to the method of Tada and Okumura. ${ }^{23)}$ At 5 days after the first sensitization, the rats were given $0.5 \mathrm{mg}$ of DNBS-As as a booster.

4) Measurement of Serum IgE Level

The level of IgE in the serum was determined by means of PCA according to Tada and Okumura's method. ${ }^{23)}$ Ten BrownNorway rats and 5 Wistar rats were em. ployed for this experiment. Blood samples were taken from the tail vein of the rats at 6 , $10,15,20,25$, and 30 days after the first sensi. tization. The serum was kept at $-20^{\circ} \mathrm{C}$ until PCA reaction was carried out.

5) Definition of Dose of Anesthetics

Avoidance action of the anesthetized rats from hot water $\left(45^{\circ} \mathrm{C}\right)$ at $30 \mathrm{~min}$ after the intraperitoneal administration of anesthetics was used to define the dose of anesthetics yielding an anesthetized condition of rats. Nembutal ${ }^{\circledR}$-administered rats were divided into 4 groups of 5 Wistar rats which were received 20,25 , and $30 \mu \mathrm{g}$ per rat weight $(\mathrm{g}$ ) of $\mathrm{Nembutal}^{\circledR}$, and saline as a control. Urethane-administered rats were divided into 6 groups of 5 Wistar rats which were received $500,600,700,800$, and $900 \mu \mathrm{g}$ per rat weight (g) of urethane, and saline as a control.

6) Measurement of Respiratory Resistance under Anesthetized and Nonanesthetized Condition

The respiratory resistance of the rats was measured on the basis of the principle of oscillation. ${ }^{24)}$ We applied a system to analyze the airway hyperreactivity which employed a machine for small experimental animals (Animal Asto TMC-2100, Chest Co., Ltd., Tokyo, Japan). Nonsensitized Wistar rats were divided into 3 groups of 5 rats which were the Nembutal ${ }^{\circledR}$-administered group, urethane-administered group and nonanesthetized group. The anesthetized and nonanesthetized rats were placed into a plastic box, which was $10 \mathrm{~cm}$ in inner diameter and $20.7 \sim 25.7 \mathrm{~cm}$ in length. Air pressure in the form of a sine wave $(30 \mathrm{~Hz})$ was applied to the rat from the rear of the box, and the air flow per second at the front of the face was measured with a pneumotachograph through a conical plastic mask. The air pressure in the box was extracted by a transducer. The sign of the air pressure $(\mathrm{P})$ and the volume of air flow (V) were transmitted to the AMP and the respiratory resistance was calculated from the ratio of $\mathrm{P}$ and $\mathrm{V}$. Acetylcholine was administered by an ultrasonic nebulizer (model NB-83D ; Chest Co., Ltd., Tokyo, Japan, 2350 $\sim 2600 \mathrm{~Hz}$ ) and by intravenous injection. On nebulization, the volume of inner fluid was $2 \mathrm{ml}$ in the drug chamber with an Animal-Asto TMC-2100. Measurement of the respiratory resistance $(\Delta \mathrm{P} / \mathrm{V})$ was carried out after injection and inhalation of acetylcholine, and continued until respiratory resistance returned to the baseline value.

7) Determination of Nebulization Time, Antigen Concentration and Changes in Antigenicity during Nebulization

a) Determination of nebulization time

The solution of the DNBS-As antigen was nebulized with a nebulizer attached to an Animal Asto TMC-2100. The time for nebulization of the DNBS-As antigen was set at $2.5,5$, and $10 \mathrm{~min}$. After the nebulization, the aerosol was recovered and centrifuged for $5 \mathrm{~min}$ at $3000 \mathrm{rpm}$, and the solution of the DNBS-As antigen was collected. The recovery of the aerosol was carried out according to a technique described previously. ${ }^{25,26)}$

b) Measurement of antigen concentration

This was performed by the method of Lowry et al. ${ }^{27)}$ using the Folin phenol reagent of Folin and Ciocalteu. ${ }^{28)} \mathrm{A}$ standard curve for protein concentration was prepared with 
crystallized bovine serum albumin. The protein concentrations of the residual solution of antigen in the drug chamber and the recovered solution of antigen after nebulization were determined. Levels of $0.5,1,2,3,5$, and 10 $\mathrm{mg} / \mathrm{ml}$ as the concentration of antigen were used with nebulization for $5 \mathrm{~min}$.

c) Changes in antigenicity of antigen during nebulization

The antigenicity of the DNBS-As was measured by enzyme-linked immunosorbent assay (ELISA). ${ }^{29,30)}$ Solutions of DNBS-As (protein concentration, $0.5 \mu \mathrm{g} / \mathrm{ml}$ ) recovered after inhalation for $2.5,5$, and $10 \mathrm{~min}$ and the DNBS-As solution prior to inhalation (protein concentration, $0.5 \mu \mathrm{g} / \mathrm{ml}$ ) were coated onto the wells. Rat anti-DNBS-As IgE antibody was obtained from the serum of rats sensitized with DNBS-As. Precipitation with ammonium sulfate, DEAE-Sephacel ionexchange chromatography and the PCA reaction were carried out to isolate and purify the rat anti-DNBS-As IgE antibody with low molecular weight.

8) Judgment of Early and Late Phase Responses

Wistar and Brown-Norway rats employed for this experiment. Inhalation of DNBS-As by sensitized rats under non-anesthetized condition was carried out at every day after finishing the booster dose for 5 min until the early and late phase responses were observed. On nebulization of DNBS-As solution, the volume of inner fluid was $2 \mathrm{ml}$ and the concentration of DNBS-As was $1 \mathrm{mg} / \mathrm{ml}$ in the drug chamber with an Animal-Asto TMC-2100. The respiratory resistance of the rats were measured for $30 \mathrm{~min}$ after nebulization of DNBS-As solution, and subsequently measured for $5 \mathrm{~min}$ at every an hour up to $6 \mathrm{~h}$ after nebulization of DNBS-As solution. The appearance of early and late phase responses was judged by comparing the magnitude of peak of respiratory resistance before and after the nebulization of DNBS-As. In addition, the time of the appearance of increased res- piratory resistance after the nebulization of DNBS-As was used to distinguish between early and late phase responses. An early phase response was defined as one in which the peak of respiratory resistance within 30 min after the nebulization of DNBS-As increased to more than twice the magnitude of the baseline. A late phase response was defined as one in which the peak of respiratory resistance from $30 \mathrm{~min}$ to $6 \mathrm{~h}$ after the nebulization increased to more than twice the magnitude of the baseline.

9) Drug and Reagents

2, 4-Dinitrobenzene sulfonic acid sodium salt was purchased from Tokyo Kasei Inc., Ltd. (Tokyo, Japan). Solution of killed Bordetella pertussis was purchased from Kaken Chemical Ltd. (Osaka, Japan). Acetylcholine chloride, sodium carbonate (anhydrous), ethyl ether and urethane were purchased from Nacalai Tesque Inc. (Kyoto, Japan). Nembutal ${ }^{\circledR}$ injection was purchased from Abbot Laboratories (Chicago, IL, USA). Cupric sulfate (crystalline powder) and sodium tartrate were purchased from Kanto Chemical Co., Inc. (Tokyo, Japan). Phenol reagent was purchased from Wako Pure Ind. Ltd. (Osaka, Japan). POD-goat anti-rat $\operatorname{IgG}(\mathrm{H}+\mathrm{L})$ was purchased from Biorad Laboratories (CA, USA). ABTS was purchased from Sigma Biochem. Co., Ltd. (Mo, USA). Unless otherwise stated, only reagent-grade chemicals were employed as other reagents.

\section{RESULTS}

\section{1) Responsiveness to acetylcholine of tracheal strips derived from nonsen- sitized rats}

Four tracheal strips were prepared which consisted of the 1st, 5th, 10th and 15th tracheal cartilage rings. Concentrations of acetylcholine ranging from $0.5 \times 2^{-5}$ to 0.5 $\mathrm{mg} / \mathrm{ml}$ were used for this experiment. With a tracheal strip consisting of the 15th tracheal cartilage ring, the strongest contraction was 


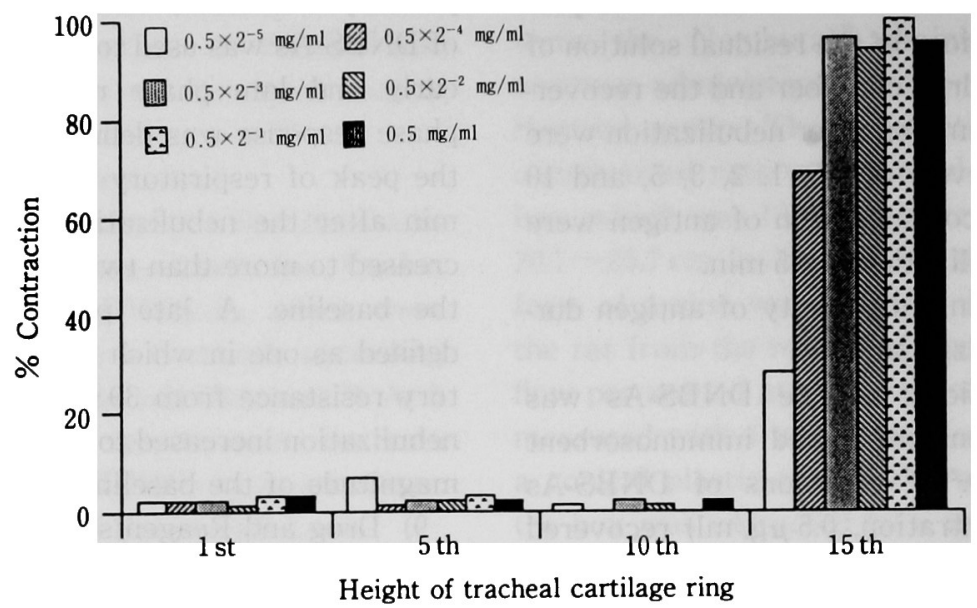

Fig. 1 Contraction of tracheal strips derived from nonsensitized rats in response to acetylcholine. Throughout the experiments, the height of the maximal contraction was taken as $100 \%$ contraction.

Ordinate : Relative maximal contraction at various concentrations of acetylcholine. Abscissa : Acetylcholine concentration applied to tracheal strips derived from tracheal cartilage rings of various heights.

observed at the various concentrations of acetylcholine. With the tracheal strips consisting of the 1st, 5th and 10th tracheal cartilage rings, contraction was not observed completely at various concentrations of acetylcholine (Fig. 1). On this basis, tracheal strips consisting of the 15th tracheal cartilage ring were employed in subsequent experiments.

2) Changes in acetylcholine activity during nebulization

After acetylcholine at various concentrations had been nebulized for $5 \mathrm{~min}$, the acetylcholine solution was recovered. The acetylcholine activity was determined with tracheal strips consisting of the 15th tracheal cartilage ring derived from nonsensitized rats. The contraction of the tracheal strips in response to acetylcholine before nebulization was not significantly different from that in response to acetylcholine after nebulization at the various concentrations (Fig. 2). From the above results, it was found that, in the range from $10^{-4}$ to $10^{-3} \mathrm{M}$, the biological activity of acetylcholine for tracheal responsiveness did

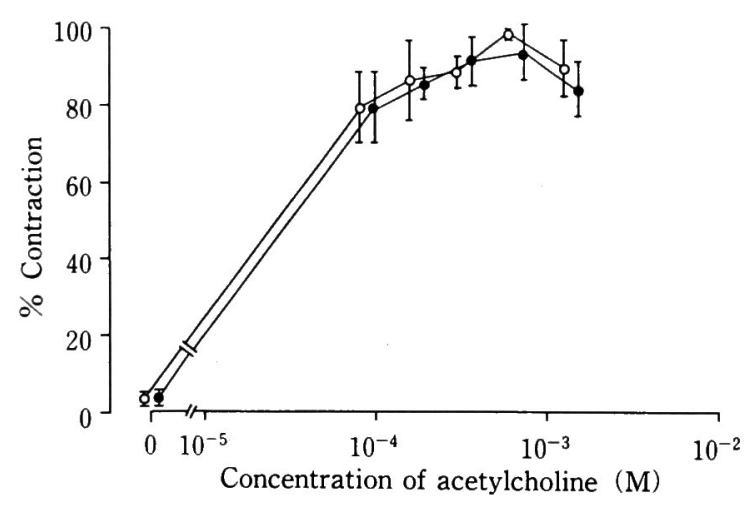

Fig. 2 Changes in acetylcholine activity during nebulization.

Ordinate : Relative maximal contraction. Abscissa: Concentration of acetylcholine. $n=3$. $\$$ : before nebulization, mean $\pm \mathrm{SE} ; \boldsymbol{\phi}$ : after nebulization, mean $\pm \mathrm{SE}$.

not change during the nebulization of acetylcholine.

3) Comparative responsiveness of tracheal strips derived from sensitized and nonsensitized Wistar rats for acetylcholine and DNBS-As antigen 


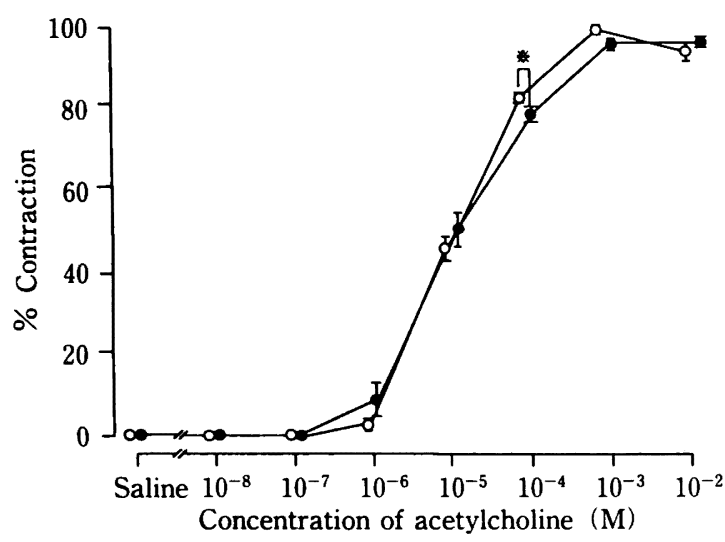

Fig. 3 Comparison of contractions induced by acetylcholine in tracheal strips derived from nonsensitized and sensitized rats.

Ordinate: Relative maximal contraction at various concentration of acetylcholine. Abscissa : Concentration of acetylcholine. $n=5$. $*: p<0.05$. $\Phi:$ tracheal strips derived from nonsensitized rats, mean $\pm \mathrm{SE} ; \quad$ : tracheal strips derived from sensitized rats, mean $\pm \mathrm{SE}$.

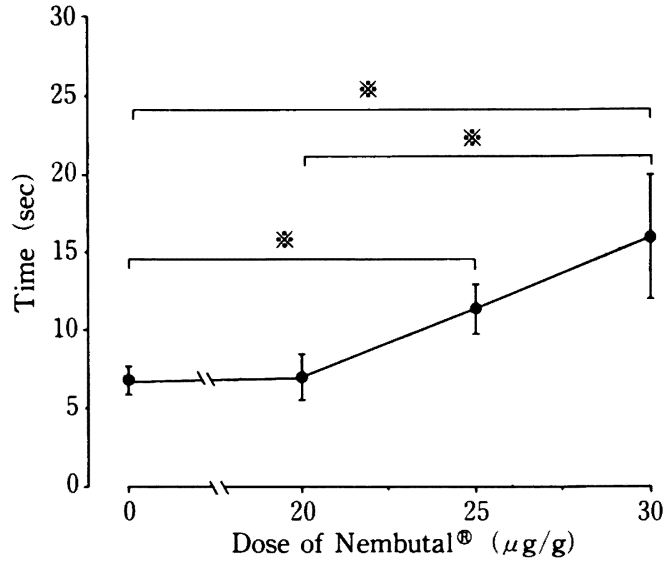

Fig. 4 Avoidance action of Nembutal ${ }^{\circledR}$-administered rats from hot water $\left(45^{\circ} \mathrm{C}\right)$.

Ordinate: The time required for anesthetized rats to pull their tails from the hot water. Abscissa : Administered dose of Nembutal ${ }^{\circledR} . n=5, *$ : $\mathrm{p}<0.05$. $:$ mean $\pm \mathrm{SE}$. The temperature of the water was $45^{\circ} \mathrm{C}$.

Table 1 Contraction of tracheal strips derived from nonsensitized and sensitized rats in response to DNBS-As. The numbers and ratios of the tracheal strips contracted by DNBS-As are indicated in Table 1 . The relative ratio is expressed as the number of contracted tracheal strips divided by the total number of rats used in the experiment.

\begin{tabular}{lccccc}
\hline \multirow{2}{*}{$\begin{array}{l}\text { Tracheal strip } \\
\text { source }\end{array}$} & $0.1 \mu \mathrm{g} / \mathrm{ml}$ & $1 \mu \mathrm{g} / \mathrm{ml}$ & $10 \mu \mathrm{g} / \mathrm{ml}$ & $100 \mu \mathrm{g} / \mathrm{ml}$ & Total \\
\cline { 2 - 6 } & $0 / 5(0 \%)$ & $2 / 5(40 \%)$ & $1 / 5(20 \%)$ & $0 / 5(0 \%)$ & $3 / 5(60 \%)$ \\
Sensitized rats & $0 / 5(0 \%)$ & $0 / 5(0 \%)$ & $0 / 5(0 \%)$ & $0 / 5(0 \%)$ & $0 / 5(0 \%)$ \\
Nonsensitized rats & &
\end{tabular}

Sensitized rats at 8 to 14 days after the beginning of sensitization using acetylcholine and DNBS-As were employed for this experiment. At a concentration of $10^{-4} \mathrm{M}$ acetylcholine, the contraction of tracheal strips derived from sensitized rats was significantly different from that of strips derived from non-sensitized rats; however, at other concentrations of acetylcholine, the contraction of both strips was not significantly different (Fig. 3). In both groups, tike $\mathrm{ED}_{50}$ of acetylcholine ranged from $10^{-5}$ to $10^{-4} \mathrm{M}$. At con centrations of from 0.6 to $100 \mu \mathrm{g} / \mathrm{ml}$ of DNBS-As, the contraction of tracheal strips was observed in $60 \%$ of the examined strips derived from sensitized rats (Table 1).

4) Respiratory resistance following the intravenous administration and inhalation of acetylcholine under anesthetized and nonanesthetized conditions

a) Definition of dose of anesthetics

A delay in the avoidance action was observed at a concentration of $30 \mu \mathrm{g}$ per rat weight (g) of Nembutal ${ }^{\circledR}$ (Fig. 4). In addition, from a concentration of $800 \mu \mathrm{g}$ to $900 \mu \mathrm{g}$ per rat weight $(\mathrm{g})$ of urethane, a delay in the avoidance action was observed (Fig. 5).

b) Comparison of respiratory resistance under anesthetized and nonanesthetized condition after the intravenous adminis- 


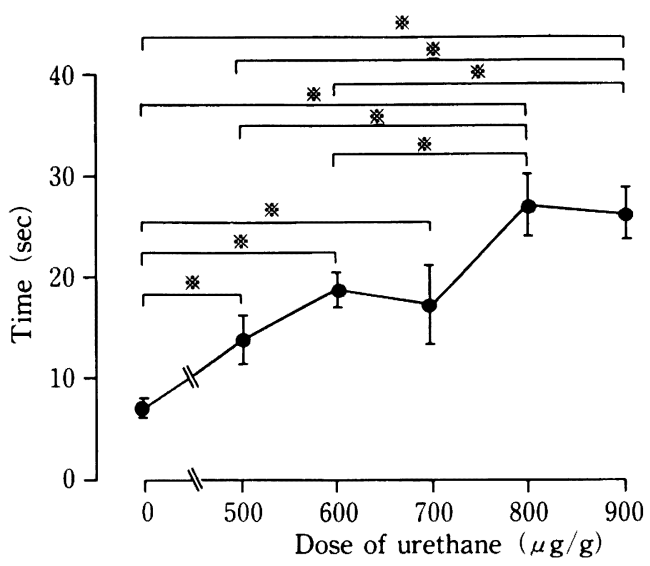

Fig. 5 Avoidance action of urethane-administered rats from hot water.

Ordinate: The time required for anesthetized rats to pull their tails from hot water. Abscissa : Administered dose of urethane. $※: p<0.05$. Other details as in Fig. 4.

tration and inhalation of acetylcholine

In the Nembutal ${ }^{\circledR}$-administered group, 30 $\mu \mathrm{g}$ per rat weight $(\mathrm{g})$ of $\mathrm{Nembutal}^{\circledR}$ was administered. In the urethane-administered group, $900 \mu \mathrm{g}$ per rat weight $(\mathrm{g})$ of urethane was administered. At $30 \mathrm{~min}$ after the administration of the anesthetics, acetylcholine at various concentrations was intravenously administered, and respiratory resistance was measured. The respiratory resistance in the nonanesthetized group increased with the increase in administered acetylcholine. However, in the Nembutal ${ }^{\circledR}$. and urethaneadministered groups, the respiratory resistance did not change after the intravenous administration of acetylcholine (Fig. 6). After the inhalation of acetylcholine, the respiratory resistance of rats in the nonanesthetized group increased with the increase in inhalated acetylcholine, but that of rats in the anesthetized groups did not change with the increase in inhalated acetylcholine (Fig. 7).

\section{5) Relationship between concentration} of DNBS-As and volume of aerosol

For the inhalation of antigen (DNBS-As) in sensitized rats, the concentration of DNBSAs in the drug chamber must be decided so as

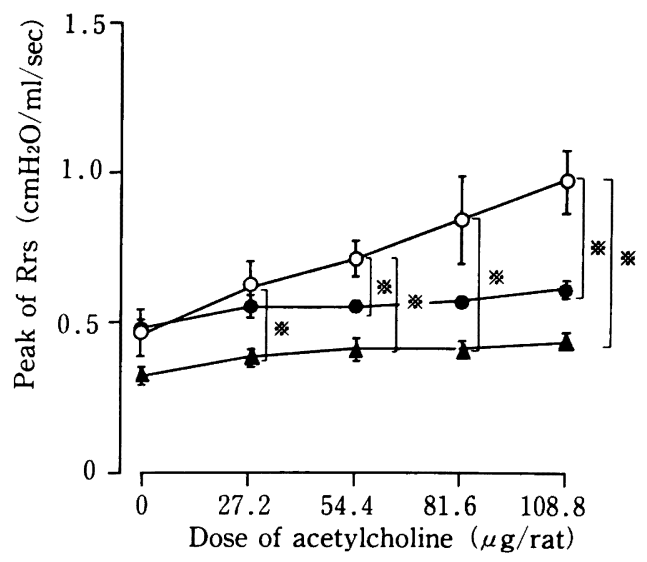

Fig. 6 Respiratory resistance after the intravenous administration of acetylcholine under anesthetized and nonanesthetized conditions.

Ordinate: Peak of respiratory resistance $\left(\mathrm{cmH}_{2} \mathrm{O} /\right.$ $\mathrm{ml} / \mathrm{sec}$ ). Abscissa : Administered dose of acetylcholine. $n=5, ※: p<0.05$. $\$:$ nonanesthetized rats, mean $\pm \mathrm{SE} ; \boldsymbol{\Phi}:$ Nembutal ${ }^{\circledR}$-administered rats, mean $\pm \mathrm{SE} ; \overline{\mathbf{A}}_{\mathbf{1}}$ : urethane-administered rats, mean $\pm \mathrm{SE}$.

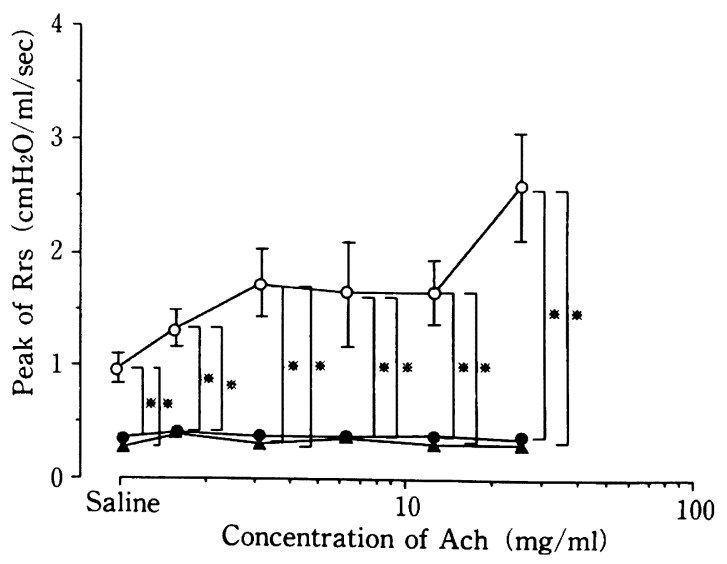

Fig. 7 Respiratory resistance after the inhalation of acetylcholine under anesthetized and nonanesthetized conditions.

Ordinate: Differences in peak of respiratory resistance between inhalation of physiological saline and acetylcholine. Abscissa: Inhalated dose of acetylcholine, $25 \mathrm{mg} / \mathrm{ml}$ of acetylcholine was diluted with physiological saline. $n=5, \%$ : $\mathrm{p}<0.05$. $\Phi$ : nonanesthetized rats, mean $\pm \mathrm{SE}$;

$\Phi$ : Nembutal ${ }^{\circledR}$-administered rats, mean $\pm \mathrm{SE}$;

$\overline{1}$ : urethane-administered rats, mean $\pm \mathrm{SE}$. 


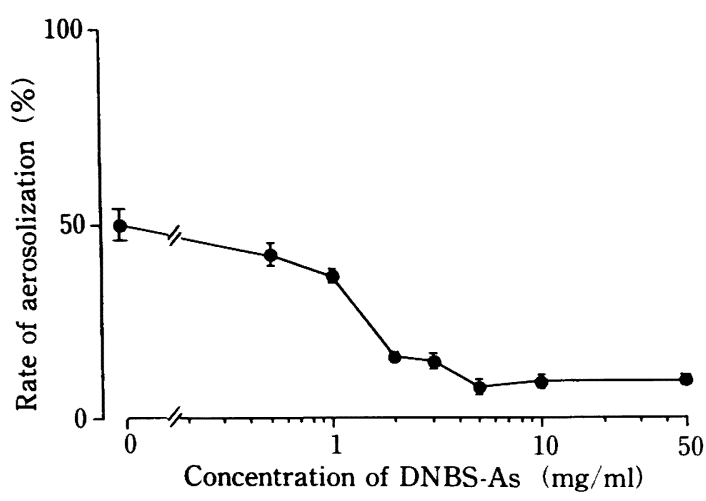

Fig. 8 Relationship between the rate of aerosolization and concentrations of DNBS-As in the drug chamber.

The volume of the inner fluid in the drug chamber was $2 \mathrm{ml}$. The nebulization time was $5 \mathrm{~min}$. Ordinate: Rate of aerosolization. Abscissa: Con centration of DNBS-As $(\mathrm{mg} / \mathrm{ml}) . \mathrm{n}=5$. $\mathbf{\Phi}$ : mean $\pm \mathrm{SE}$.

to provide a sufficient volume of antigen to the target organ of the sensitized rats. First, the rate of aerosolization at various concentrations of DNBS-As in the drug chamber was examined. An increased concentration of DNBS-As led to a decreased aerosolization rate (Fig. 8). In subsequent experiments, 1 $\mathrm{mg} / \mathrm{ml}$ of DNBS-As was used for inhalation by means of an Astogram.

6) Changes in protein concentration and antigenicity of DNBS-As solution after nebulization

The protein concentration of DNBS-As solution in the drug chamber before nebulization was $0.39 \pm 0.02 \mathrm{mg} / \mathrm{ml}$ (mean $\pm \mathrm{SE}$ ). The protein concentration of the collected DNBSAs solution after nebulization for $2.5 \mathrm{~min}, 5$ $\mathrm{min}$ and $10 \mathrm{~min}$ was $0.67 \pm 0.07 \mathrm{mg} / \mathrm{ml}, 0.53 \pm$ $0.03 \mathrm{mg} / \mathrm{ml}$, and $0.53 \pm 0.05 \mathrm{mg} / \mathrm{ml}$, respectively, based on measurements by the method of Folin-Lowry. The volume of DNBS-As solution collected after nebulization for $2.5 \mathrm{~min}, 5$ $\mathrm{min}$, and $10 \mathrm{~min}$ was $0.1 \pm 0.03 \mathrm{ml}, 0.27 \pm 0.07$ $\mathrm{ml}$, and $0.46 \pm 0.07 \mathrm{ml}$, respectively. Calculating from these results, the total quantity of protein in the recovered solution of DNBS-As was $65 \pm 2.0 \mu \mathrm{g}, 144 \pm 1.8 \mu \mathrm{g}, 244 \pm 3.5 \mu \mathrm{g}$ after

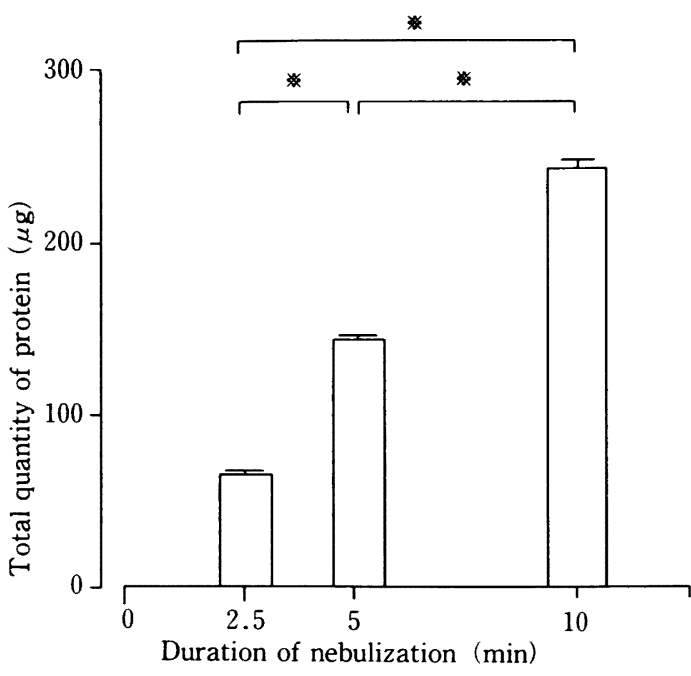

Fig. 9 Recovered total quantity of protein after nebulization of DNBS-As.

Ordinate: Total quantity of protein. Abscissa : Duration of nebulization. $n=5, *: p<0.01$. $\lceil:$ mean \pm SE.

$2.5 \mathrm{~min}, 5 \mathrm{~min}$, and $10 \mathrm{~min}$ of nebulization, respectively (Fig. 9). The changes in antigenicity following the nebulization of DNBSAs were estimated using anti DNBS-As IgE (IgE with a low molecular weight) by means of ELISA. The absorbance at $415 \mathrm{~nm}$ was $0.6,0.5$, and 0.55 after nebulization for $2.5 \mathrm{~min}$, $5 \mathrm{~min}$, and $10 \mathrm{~min}$, respectively, while it was 1.0 before nebulization. Taking the absorbance at $415 \mathrm{~nm}$ of the solution of DNBS-As before nebulization as representing $100 \%$ of the antigenicity of DNBS-As, the relative antigenicities after various nebulization times were estimated (Fig. 10). The results indicated that the total quantity of DNBS-As antigen acting on the smooth muscle of the trachea and bronchi was about $39 \mu \mathrm{g}$ for 2.5 $\min , 72 \mu \mathrm{g}$ for $5 \mathrm{~min}$ and $134 \mu \mathrm{g}$ for $10 \mathrm{~min}$ of nebulization, respectively. In addition, it was clarified that although the antigenicity of DNBS-As decreased following nebulization, the antigenicity did not change appreciably with different intervals of nebulization.

7) Appearance of airway responses in sensitized rats 


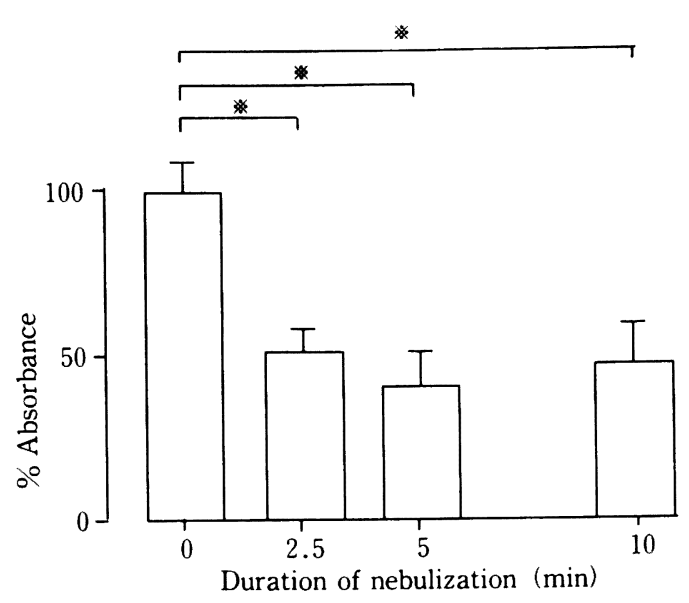

Fig. 10 Change in antigenicity of recovered DNBS-As solution after nebulization.

The absorbance at $415 \mathrm{~nm}$ of the DNBS-As solution before nebulization was taken as representing $100 \%$ antigenicity. Ordinate : Relative antigenicity of recovered DNBS-As solution. Abscissa:Duration of nebulization. $\mathrm{n}=5, ※$ : $\mathrm{p}<0.01$. $\frac{1}{\mathrm{~N}}:$ mean $\pm \mathrm{SE}$.

a) Changes of $\operatorname{IgE}$ level after sensitization

The serum $\operatorname{IgE}$ levels in the Wistar and Brown-Norway rats reached a peak at 15 days after sensitization and began to decline at 20 days after the sensitization (Fig. 11).

b) Appearance of early and late phase responses

The rate of appearance of the early and late phase responses in the case of nebulization of antigen for $5 \mathrm{~min}$ was higher than that for 10 min (data not shown). A study of the relationship between the course of sensitization and the rate of the appearance of airway responses revealed that early phase responses

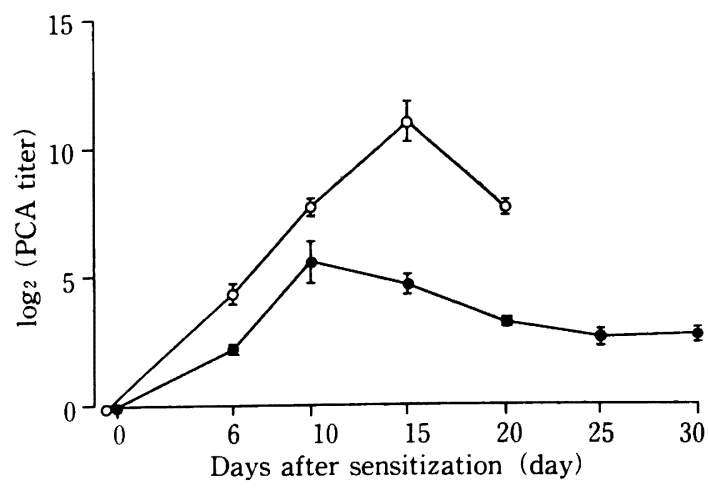

Fig. 11 Change in $\operatorname{IgE}$ level after sensitization. Ordinate $: \log _{2}$ (PCA titer). Abscissa: Time after sensitization. $\$$ : Brown-Norway rats (mean $\pm \mathrm{SE}), \mathrm{n}=10$ : $\Phi^{\top}$ : Wistar rats (mean $\pm \mathrm{SE}$ ), $\mathrm{n}=5$.

readily appeared in the rats $16-30$ days after sensitization. On the other hand, late phase responses appeared in rats 8-15 days after sensitization (Table 2).

\section{DISCUSSION}

In general, it has been found that rats are not so sensitive to chemical mediators. On the other hand, guinea pigs display a strong sensitivity to chemical mediators. In the present study, we examined the sensitivity of the trachea for acetylcholine using tracheal strips. In order to select appropriate materials which contracted strongly in response to acetylcholine, tracheal strips originating from various positions in the trachea of nonsensitized rats were evaluated. As a result, tracheal strips which consisted of the 15th

Table 2 Appearance rates on early and late phase responses in sensitized rats. The appearance rate is expressed as the number of rats in which an early or late phase response was evoked divided by the total number of rats used in the experiment.

\begin{tabular}{lcc|ccc}
\hline Duration of nebulization (min) & \multicolumn{3}{c}{5} \\
\hline Time after sensitization (days) & \multicolumn{2}{c|}{$8-15$} & \multicolumn{2}{c}{$16-30$} \\
\hline Strain of rat & W & B-N & W & B-N \\
Early phase responses & $2 / 10(20 \%)$ & $6 / 22(27 \%)$ & $3 / 5(60 \%)$ & $5 / 15(33 \%)$ \\
Late phase responses & $1 / 10(10 \%)$ & $4 / 22(18 \%)$ & $0 / 5(0 \%)$ & $0 / 15(0 \%)$ \\
\hline
\end{tabular}

$\mathrm{W}:$ Wistar rats, B-N : Brown-Norway rats 
tracheal cartilage ring were found to contract strongly with various concentrations of acetylcholine. At the level of the 15th cartilage ring, the anatomical findings correspond to a position which contains abundant smooth muscle.

On this basis, an experiment was undertaken to investigate whether or not the activity of acetylcholine changed after nebulization employing the 15th ring of tracheal cartilage. The data obtained indicated that the activity of acetylcholine did not change appreciably between before and after the nebulization of acetylcholine. On the other hand, the concentration of acetylcholine ranged from $10^{-5}$ to $10^{-4} \mathrm{M}$ for $50 \%$ contraction of the tracheal strips in the present study on rats. Such concentrations of acetylcholine are broadly equal to those demonstrating $50 \%$ contraction of smooth muscle in bovine trachea. ${ }^{31}$

Furthermore, we investigated whether or not the sensitivity for acetylcholine was increased in tracheal strips originating from sensitized rats. The difference in $E D_{50}$ between the contraction of tracheal strips from sensitized rats and those from nonsensitized rats was not found to be significant. It was evident that the sensitivity for acetylcholine of isolated trachea from sensitized rats did not increase. In addition, in in vivo experiments, the respiratory resistance of rats was measured following intravenous administration and inhalation of acetylcholine under anesthetized and nonanesthetized conditions. In Nembutal ${ }^{\circledR}$. and urethane-administered groups, the respiratory resistance did not change after the intravenous administration and inhalation of acetylcholine.

However, under the nonanesthetized condition, the respiratory resistance increased with the increase in administered acetylcholine. From the above results, in the subsequent experiment, the respiratory resistance of rats was measured under the nonanesthe- tized condition. After intravenous administration, the respiratory resistance increased dose-responsely in the range of 27.2 to 108.8 $\mu \mathrm{g}$ as the amount of acetylcholine. After inhalation of acetylcholine, the respiratory resistance increased in the range of 1.56 to 25 $\mathrm{mg} / \mathrm{ml}$ as the concentration of acetylcholine. Contraction of tracheal strips derived from sensitized rats was observed in $60 \%$ of antigen-administered samples.

Next, using materials from sensitized rats, the contraction of tracheal strips induced by antigen (DNBS-As) was observed and, in a further experiment, airway responses in sensitized rats under nonanesthetized conditions were examined following administration of DNBS-As by means of a nebulizer with an Astogram. The respiratory resistance, as a parameter for evaluating the airway responses of the rats, was measured by the method of oscillation. Prior to determining the respiratory resistance, the duration of nebulization and concentration of DNBS-As were decided on the basis of preliminary experiments.

For measurement of the respiratory resistance in order to evaluate the early phase response, it was found that nebulization of the antigen for $5 \mathrm{~min}$ instead of $10 \mathrm{~min}$ was best. Finally, $1 \mathrm{mg} / \mathrm{ml}$ as the concentration of DNBS-As and $5 \mathrm{~min}$ as the duration of nebulization were utilized to determine the respiratory resistance. Data for the rate of appearance of early and late phase responses indicated that the appearance rates in Wistar rats were higher than those in BrownNorway rats.

We consider that the airways of the Wistar rats were subject to slight non-specific inflammation because of being bred and fed under conventional coditions. On the other hand, the Brown-Norway rats had little non-specific inflammation of their airways because of being bred and fed under specific pathogenfree conditions. Accordingly, we infer that the airway responses of the Brown-Norway rats 
did not appear easily upon challenge with DNBS-As. Another reason for the different rates of the appearance of airway responses could be that the sensitivity to DNBS-As of Wistar rats differs from that of BrownNorway rats. Early phase responses readily appeared in the rats from day 16 to day 30 after the first sensitization. It can be suggested that the above results could have been based on non-specific inflammation of the airways according to frequent challenge with DNBS-As.

On the other hand, late phase responses appeared from day 8 to day 15 after sensitization. These results may have been related to the high levels of IgE in the circulating blood. It has been reported that $\operatorname{IgE}$ production in Wistar rats differs from that in BrownNorway rats. ${ }^{32}$ Furthermore, the dual response of the lung or skin could depend on IgE production. ${ }^{933)}$ These observations indicate that hyperresponsiveness of the airways may have appeared after the onset of the late phase response. ${ }^{34)}$ We found that late phase responses readily appeared when the level of the IgE antibody was high in the circulating blood. Previous reports have described airway hyperresponsiveness in rats under anesthesia. ${ }^{35)}$ However, in this study, we succeeded in evaluating the airway response of rats under nonanesthetized conditions.

\section{REFERENCES}

1) Booij-Noord, H., Orie, N.G.M., and de Vries, $\mathrm{K}$. : Immediate and bronchial obstructive reaction to inhalation of house dust and protective effects of disodium cromoglycate and prednisolone. J. Allergy Clin. Immunol., 48 : 344-354, 1971.

2 ) Pepys, J., Hargreave, F.E., Chan, M., et al. : Inhibitory effects of disodium cromoglycate on allergen-inhalation tests. Lancet, $2: 134$ $137,1968$.

3 ) Kondo, H., Tsuruta, M., Hayakawa, Y., et al. : Clinical studies on asthmatic children induced by Candida antigen. Jpn. J. Allergol., $33: 381-388,1984$ (in Japanese).

4 ) Chung, K.F., Becker, A.B., Lazarus, S.C., et al. : Antigen-induced airway hyperresponsiveness and pulmonary inflammation in allergic dogs. J. Appl. Physiol., 58:13471353, 1985.

5 ) Hoshino, H., Kobayashi, H., Konno, S., et al. : Allergen-induced late bronchoconstriction and airway hyperresponsiveness in guinea pig. Jpn. J. Allergol., $38: 314-325$, 1989 (in Japanese).

6 ) Robertson, D.G., Kerigan, A.T., Hargreave, F.E., et al. : Late asthmatic responses induced by ragweed pollen allergen. J. Allergy Clin. Immunol., 54:244-254, 1974.

7 ) Dolovich, J., Hargreave, F.E., Chalmers, R., et al. : Late cutaneous allergic responses in isolated IgE-dependent reactions. J. Allergy Clin. Immunol., $52: 38-46,1973$.

8 ) Behrens, B.L., Clark, L.A.F., Marsh, W., et al. : Modulation of the late asthmatic response by antigen-specific immunoglobulin $\mathrm{G}$ in an animal model. Am. Rev. Respir. Dis., $130: 1134-1139,1984$.

9 ) Shampain, M.P., Behrens, B.L., Larsen, G.L., et al. : An animal model of late pulmonary responses to Alternaria challenge. Am. Rev. Respir. Dis., 126 : 492-498, 1982.

10) Terasi, Y., Yukawa, T., Fukuda, T., et al. : Late phase response in the guinea pig airway caliber following inhalated antigen exposure. I. Comparative study of passively and actively sensitized models. Jpn. J. Allergol., 37 : 980-991, 1988 (in Japanese).

11) Hamel, R., McFarlane, C.S., and FordHunchinson, A.W. : Late pulmonary responses induced by Ascaris antigen in conscious squirrel monkeys. J. Appl. Physiol., 61:2081-2087, 1986.

12) Abraham, W.M., Delehunt, J.C., Yerger, L., et al. : Characterization of a late phase pulmonary response after antigen challenge in allergic sheep. Am. Rev. Respir. Dis., $128: 839$ 844,1983

13) Eidelman, D.H., Bellofiore, S., and Martin, J. D. : Late airway responses to antigen challenge in sensitized inbred rats. Am. Rev. Respir. Dis., 137 : 1033-1037, 1988.

14) Shishikura, T., Yamada, M., Oguro, K., et al. : Induction of airway hyperresponsiveness in allergic rats. Int. J. Tiss. Reac., $12: 341-$ $346,1990$.

15) Stotland, L.M., and Share, N.N. : Active bronchial anaphylaxis in the rat. Can. J. Physiol. Pharmacol., 52 : 1114-1118, 1974.

16) Nakamura, M., Saitoh, S., Yamashiro, Y., et al. : Inhibitory action of pentobarbital 
sodium on the platelet aggregation induced by PAF. Jpn. J. Physiol., 41 : s110, 1991.

17) Fukuda, T., Akutsu, I., Numano, T., et al. : Inhibition of antigen-induced late asthmatic response and bronchial hyperresponsiveness by cyclosporin A. Jpn. J. Allergol., 39: 483487, 1990 (in Japanese).

18) Akutsu, I., Fukuda, T., Numano, T., et al. : Inhibitory effect of FK-506 on the development of late asthmatic response and the increased bronchial responsiveness. Jpn. J. Allergol., $39: 605-609,1990$ (in Japanese).

19) Castillo, J.C., and De Beer, E.J. : The tracheal chain. I. A preparation for the study of antispasmodics with particular reference to bronchodilator drugs. J. Pharmacol. Exp. Ther., $90: 104-109,1947$.

20) Akcasu, A.: The Physiologic and pharmacologic characteristics of the tracheal muscle. Arch. Int. Pharmachodyn., 122 : 201207, 1959.

21) Strejan, J., and Campbell, D.H. : Hypersensitivity to Ascaris antigens. 1. Skinsensitizing activity of serum fractions from guinea pigs sensitized to crude extracts. J. Immunol., $98: 893-900,1967$.

22) Eisen, H.N., Belman, S., and Carsten, M.E. : The reaction of 2,4-dinitrobenzenesulfonic acid with free amino groups of proteins. J. Am. Chem. Soc., 75：4583-4585, 1953.

23) Tada, T., and Okumura, K. : Regulation of homocytotropic antibody formation in the rat. I. Feed-back regulation by passively administered antibody. J. Immunol., $106: 1002-$ 1011, 1971.

24) Mead, J. : Control of respiratory frequency. J. Appl. Physiol., 15:325-336, 1960.

25) Kosugi, T., Saitoh, S., Tamaki, N., et al. : Inhalation of platelet-activating factor increases respiratory resistance in rats: Determination by means of an astograph under nonanesthetized conditions. Laryngoscope, 103(4) : 428-430, 1993.
26) Kosugi, T., Nakamura, M., Noguchi, S., et al. : Effect of ultrasonic nebulization of Miraclid $^{\circledR}$ on the proteolytic activity in tracheobronchial secretions of rats. Laryngoscope, 99(12) : 1281-1285, 1989.

27) Lowry, O.H., Rosebrough, N.J., Farr, A.L., et al. : Protein measurement with the Folin phenol reagent. J. Biol. Chem., 193:265-275, 1951.

28) Folin, O., and Ciocalteu, V.: On tyrosine and tryptophan determinations in proteins. J. Biol. Chem., 73 : 627-649, 1927.

29) Engvall, E., and Perlmann, P.: Enzymelinked immunosorbent assay, ELISA. III. Quantitation of specific antibodies by enzyme-labelled antiimmunoglobulin in antigen-coated tubes. J. Immunol., $109: 129$ 135, 1972.

30) Hanashiro, K., Tamaki, N., Nakamura, M., et al. : Proposal of the new concepts of antiallergic drugs from the result of animal experiments. J. J. Inf., 14 (6) : 499-507, 1994 (in Japanese).

31) Barners, P.J., Cuss, F.M., and Palmer, J.B. : The effect of airway epithelium on smooth muscle contractility in bovine trachea. Br. J. Pharmac., 86: 685-691, 1985.

32) Murphey, S.M., Brown, S., Miklos, N., et al. : Reagin synthesis in inbred strains of rats. Immunology, $27: 245-253,1974$.

33) Solley, G.O., Gleich, G.J., Jordon, R.E., et al. : The late phase of the immediate wheal and flare skin reaction. J. Clin. Invest., $58: 408$ 420, 1976.

34) Marsh, W.R., Irvin, C.G., Murphy, K.R., et al. : Increases in airway reactivity to his tamine and inflammatory cells in bronchoalveolar lavage after the late asthmatic response in an animal model. Am. Rev. Respir. Dis., $131: 875-879,1985$.

35) Misawa, M., and Sugiyama, Y. : An airway hyperresponsiveness model in rat allergic asthma. Jpn. J. Allergol., 42 : 107-114, 1993. 